\section{Biological Principles of Nanostructured Hydroxyapatite Associated With Metals: A Literature Review}

\section{Abstract}

The aim of this paper is to present, in the light of literature, a comprehensive review, by reviewing the literature related to bone grafts, biomaterials (BM) and nanotechnology containing five metals ( $\mathrm{Zn}, \mathrm{Fe}, \mathrm{Sr}, \mathrm{Mg}$ and $\mathrm{Mn}$ ) with a view of an unprecedented experimental research support evaluation of the biocompatibility of these materials for human implantation. The BM market for graft indicates a trend of using synthetic materials, to the detriment of those of biological origin, ease of its large-scale production, reproducibility, doping structure and control of their physical, chemical and morphological characteristics, enabling the association with growth factors. Understanding the bone structure and its interaction with the human body are grounds factors for the development of new research. In this context, pure hydroxyapatite (main component of bone) lacks adequate biological properties because it shows high solubility and rapid incorporation of time while the materials are on the market have only osteoconductive properties, ie still not known any with ideal property. Was performed with a bibliographic levamento bone substituitos descriptor, biocompatibility and metals involved ( $\mathrm{Mg}, \mathrm{Sr}, \mathrm{Zn}, \mathrm{Fe}$, $\mathrm{Mn}$ ) in Bireme databases, Medline, and lilacs, which were initially selected and journals 135 on the subject. After further screening, they remained 69 that are part of this review. The international consensus pointing hidroxipatita as a base material for bone grafting biomaterials in humans, however, alone, possesses rapid incorporation requiring doped with one or more structures to achieve satisfactory results. The Bicompatibilidade, biodegradability and osteocondutibilidade are basic characteristics of BM as well, based on these principles, translational research in the implant area has evolved, seeking changes at the molecular level bringing new attributes to BM and consequently.

Keywords: Biotecnology; Biomaterials; Nanobiomaterials; Hydroxyapatite; Bone graft; Metals

Received: September 09, 2019; Accepted: September 24, 2019; Published: September 30,2019
Moerbeck Fillho P $^{1 *}$, Barreto $\mathrm{MA}^{2}$, Medrado ARAP2, Amaral MTR ${ }^{3}$, Moerbeck LG ${ }^{4}$, Vale DS $^{5}$ and

\section{Calasans-Maia MD 6}

1 Master's Degree in Implantology from the Bahiana School of Medicine and Public Health, Salvador, Bahia, Brazil

2 Adjunct Professor of the Dentistry Course of the Bahiana School of Medicine and Public Health, Salvador, Bahia, Brazil

3 Professor at the State University of Feira de Santana, Bahia, Brazil

4 Specialist in legal dentistry Forensic at Bahiana School of Medicine and Public Health, Salvador, Bahia, Brazil

5 Graduate in Dentistry at Bahiana School of Medicine and Public Health, Salvador, Bahia, Brazil

6 Full Professor of Dentistry at the Fluminense Federal University, Niterói, Rio de Janeiro, Brazil

*Corresponding author:

Dr. Moerbeck Pio Costa Filho

”piomoerbeck@hotmail.com

Dr. Moerbeck Pio Costa Filho, Master's Degree in Implantology from the Bahiana School of Medicine and Public Health, Salvador, Bahia, Brazil.

Tel: +557132768200

Citation: Filho PM, Barreto MA, Medrado ARAP, Amaral MTR, Moerbeck LG, et al. (2019) Biological Principles of Nanostructured Hydroxyapatite Associated With Metals: A Literature Review. Insights Biomed Vol.4 No.3:13
The repair and reconstruction of bone back the beginnings of ancient civilizations. Archaeological finds from the pre-Inca period $(3,000 \mathrm{BC})$ already show the use of these materials. With the technical, scientific and industrial advancement, the search for reconstructing bone defects caused by cancer, trauma, periodontal disease is increasingly present in the routine of health professionals. With the increased demand of patients for rehabilitation, and in parallel, the search for treatments with less 
morbidity, biomaterials are bringing new possibilities for science, especially in dentistry and Ortopedia $[1,2]$.

After tooth extraction, the alveolar undergoes various dimensional changes, it forms a clot which slowly converts to a tissue matrix in a few days. The bundle bone, which is of the extraction socket, suffers resorption and loss of its original structure, which allows blood vessels invade the medullary space surrounding the provisional matrix. With remodeling, the alveolus was corticaliza with the adjacent bone, becoming one in the center and thus, bone is remodeled to form the bone trabecular [3]. The residual bone area, the repair is completed with the formation of fibrous tissue.

Biomaterials also known as heterogenous or xenogenous are grafts obtained from other species, that are chemically treated, eliminating any trace of organic material but keeping the mineral part which is similar to human bone matrix. As set according to Clemson Advisory Board for biomaterials, systematically a biomaterial is an inert substance for incorporation in a living tissue (6th Annual International Biomaterials 1974). Hydroxyapatite (HA) is the basis of such osteoconductive materials having about $60 \%$ porosity per unit volume, facilitating the migration of osteoblasts and also a better vascularization [4].

Researchers at the bone tissue engineering area are seeking to develop new biomaterials capable to act as scaffolds to allow cell migration, angiogenesis, deposition of new extracellular matrix mineralization and regeneration of this tissue more closely with the past. These materials can be produced from metallic substrates; polymeric, natural or synthetic; ceramics; or composites. The latter have physicochemical properties that the individual components would not present individually and have attracted the attention of many researchers, the possibilities of combining the advantages of different materials [2].

\section{Literature Review}

\section{Tissue bone}

The components of the tissue are divided into structural levels such as; microstructure comprising (Volkman channels, osteons, havesiano system, individual trabecular, intermediate systems, internal and external systems cincunferenciais). The macrostructure includes (cortical and cancellous bone), the sub-covers microstructure (lamellar); and the nanostructure comprises fibrillar collagen with mineral and sub-phase nanostructure including (molecular structure of the components with collagen, non-collagen proteins and mineral $[4,5]$.

The bone cortical has few blood vessels, which corresponds to $85 \%$ of baseline bone constitution one third volume of the skeleton, having low surface/volume ratio and low porosity, reshaping it is about 2-3\% per year. Since the spongy bone tissue, corresponds to approximately $15 \%$ of bone mass and two thirds of the total volume. The bone trabecular have become more dispersed favoring the increased circulation of blood vessels, carrying higher metabolic activity, is approximately $24 \%$ reshaping the year [6].

The cells that make up the fabricare: osteoclasts, osteoblasts and osteocytes. The ECM (Extra Cellular Matrix) has $65 \%$ of inorganic composition, in particular hydroxyapatite, with the presence of ions, such as $\mathrm{CO}_{3}{ }^{2-}, \mathrm{Sr}^{2+}, \mathrm{Mg}^{2+}, \mathrm{F}^{-}$between another [7]. The ECM is a complex fusion of functional, structural, and proteoglycan proteins organized in an individual and the structure itself, acting in providing strength and support strength, adhesion sites for cellular receptors, but also signaling deposits that regulate processes such as cellular proliferation and guidance, tissue repair and angiogenesis [8].

Bone tissue has only two varieties, at the macro level and microcópio: the cortical bone (dense/compact) and the spinal cord to (trabecular/spongy), whereas the nomenclature implies, their difference lies in the aggregation of their trabecular bone and invagination of blood vessels, and the cortical tissue vascularization and less rigidity, spinal cord tissue and the contrary [9].

\section{Biological tissue bone basics}

The success of grafts depends on a number of cellular, biochemical and biomechanical events. The osteoconductive property is to create a suitable framework for migration and distribution of cells involved in vascularization and bone healing, which require structural conformity and contact with the surface graft. The process varies according to the three-dimensional structure of the graft, chemical properties, porosity and degradation [10].

Osteoinduction is the migration of osteogenic cells and bone growth factors from the transplanted tissue, which infiltrate into the graft and induce pluripotent cells to multiply and differentiate into cells that compose the regenerator site (proliferation and differentiation) $[10,11]$.

Osteogenesis in the context of grafting, bone formation is property from the donor bone tissue transplanted cells. These cells are preserved by diffusion of the surrounding tissues of the host bed, until revascularization occur. Surely the bone graft incorporation of success will require the combination of these properties. These processes are extremely important, however, other physiological factors will also influence, as the graft surface texture, age and health of receptor [12].

Remodeling is the deposition and resorption activity of the initial portion triggered continuously. Thus, modification and/or bone restructuring existing in a combined phenomenon that allows bone turnover have formed [11].

The remodeling cycle is called sigma and lasts 17 weeks, involving the following stages: Rest - synthesis engine and almost absent absorption (120 to 180 uday M); Activation - osteoclastic resorption period with formation of a sharp cone (30 uday $\mathrm{M}$ ); quiescence - great osteocytic innings for maintenance and ion exchange - 1 to 2 weeks; training - intense osteoblastic activity 13 weeks [13]. Several factors are responses for bone formation and maintenance, such as genetics, physical activity, diet and system hormonal [7]. Aging is associated with decreased bone formation. The bone loss begins gradually from the fourth decade of life, and is aggravated by menopause in women, by an imbalance of resorption compared to training (biosynthesis) [14]. 


\section{Bone healing and success factors of a biomaterial}

The cell regeneration consists in reconstituting the cells themselves, allowing recovery of their functional capacity. Already the simple or scar repair is the replacement of the destroyed structures, with no possibility of restoration [15].

The bone repair model is generally illustrated in long bones occurs in five stages: blood extravasation clot formation and hematoma; subperiosteal and endosteal proliferation, bone callus formation, consolidation and remodeling [16,17].

Bone tissue has great potential spontaneous regeneration, being stimulated by mechanical forces, however, has limitations in critical defects. These defects and in situations of lack of homeostasis, there is great possibility of aesthetic and functional damage that can limit the quality of life individual $[16,17]$.

\section{Characteristics of grafting materials}

The grafting materials are classified according to their origin, and may be autologous, allogeneic, xenogenous and alloplastic. Autogenous are considered the gold standard for grafting, since it represents the only graft having features of the three osteoconductive, osteoinductive and osteogenesis and $100 \%$ of the biocompatibility, as it is done auto-transplantation. The primary negative aspect, there is the need for a donor site with dimensions compatible [16-18].

The allograft, originating from bone bank, which passes through separate treatments or in conjunction with antibiotics, lyophilization and demineralization, has osteocondutivos and osteoinductive features, being quite unsafe to use with risk of bias in its applicability $[17,18]$. The xenogenous grafts, animal, found in abundance in nature, have osteoconductive capability and serve as a framework for boné neoformation [16-18]. The alloplastic, have the same characteristics xenógenas, however, laboratory synthetic origin, and with a great variety in your presentation $[17,18]$.

\section{Evolution of biomaterials}

For thousands of years, mankind has been developing materials to replace part of their injured biological system or lost. Initially bionertes materials were used, whose goal was not cause foreign body response to bed that will get the material, and its compliance restored in parts or in its entirety. The biomimicry is based on the "area of science that is founded on the study of biological structures and functions, seeking to learn from nature and use this knowledge in different fields of science." Its evolution is conceptual and not chronological origin with the first generation, marked by empiricism where there was no aesthetic concern, but functional, with most of these materials of natural origin, called bionertes materials.

The bio-inert materials exhibit no chemical bond with the tissues such as zirconia and alumina and remained stable without integration with meio [19]. They represent the second generation, from 1970, bioactive materials, whose philosophy was, focusing on the biocompatibility and biodegradability. Were developed from common, structural materials, but with a greater knowledge of engineering, medicine and science of applied materials, which stimulate a specific biological response, resulting in a connection with the residual tissue, such as bioactive glass, synthetic hydroxyapatite Animal bioactive and composites [19]. The bioreactive materials are situated between the bioactive and bio-inert and are widely used in implantology and also in orthopedics, such as titanium, niobium, tantalum [20].

In the third and current generation, the materials are able to stimulate the response at the molecular level, characterized specifically, in accordance with its application [18,20] (Figure 1). Some minimum requirements are essential to a biomaterial become possible deployment: Biocompatibility, biodegradability, mechanical properties and appropriate three-dimensional architecture.

Biocompatibility: The main criterion of any bone substitute is that it is biocompatible, its cells must adhere and migrate to the surface to set up a new array in the region. After the implementation should not trigger an exacerbated immune response, which does not cause local inflammation to happen rejection response [21,22].

Biodegradability: Must be able to stimulate the cells to produce their own extracellular matrix. The by-products must not be

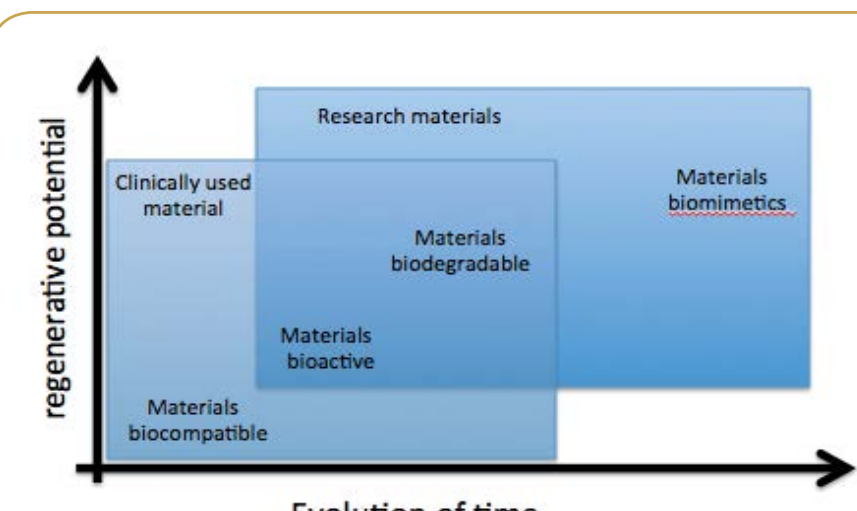

Evolution of time

Figure 1 Evolution of functioning and regenerative capacity of biomaterial over time [21].

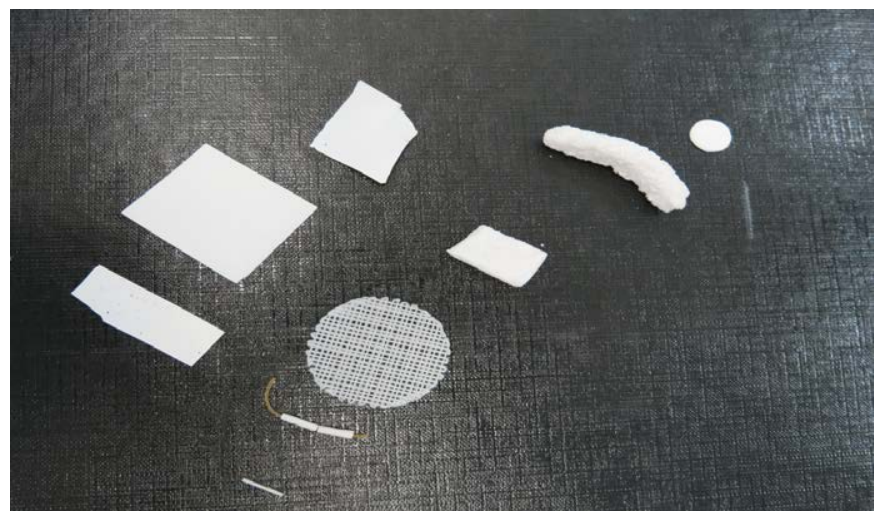

Figure 2 Example morphology of bone substitutes, according coma clinical need professional (Source: Photographed at the Brazilian Center for Physics Research/RJ). 


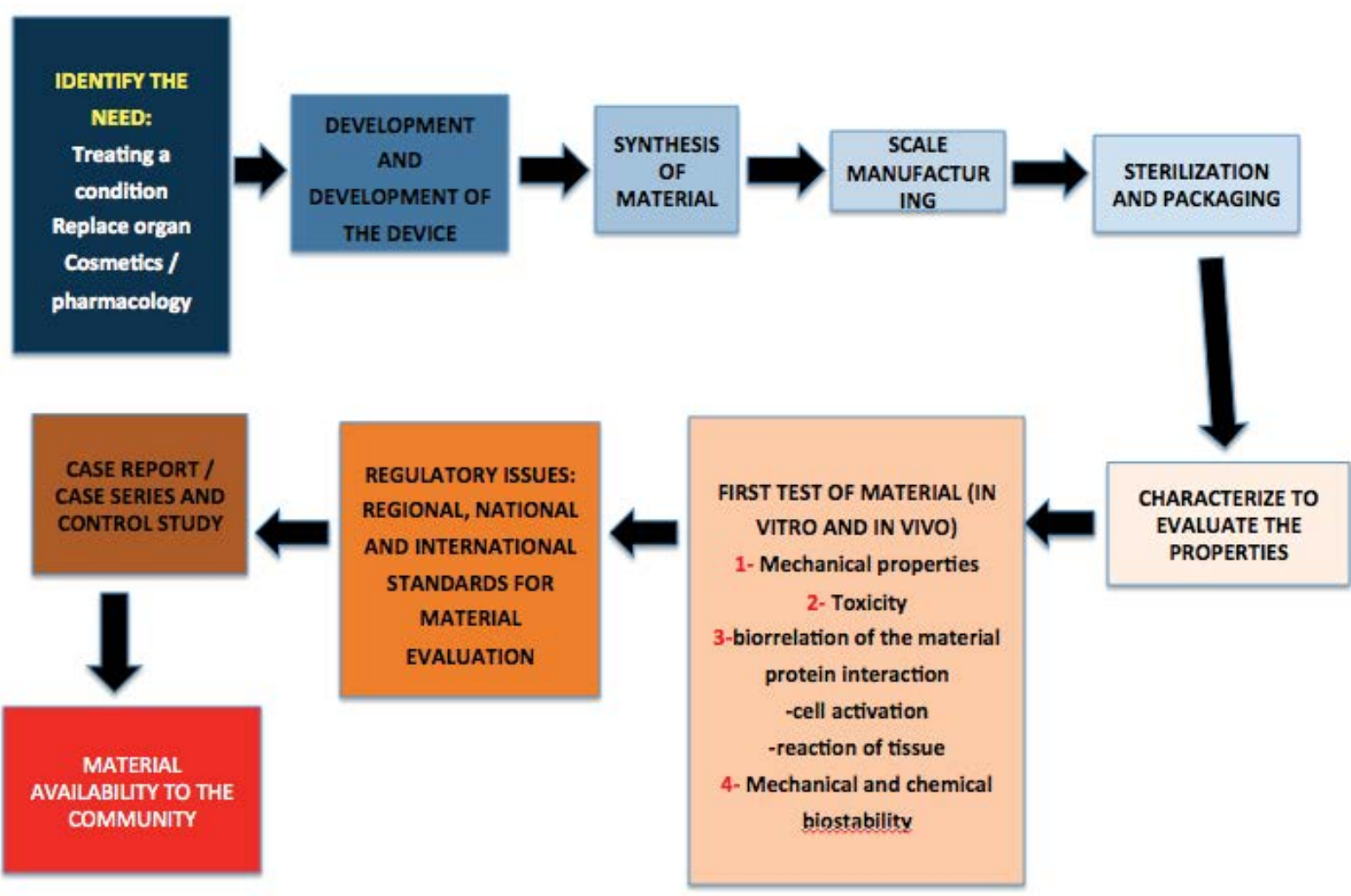

Figure 3 Organizational chart showing the cycle for developing.

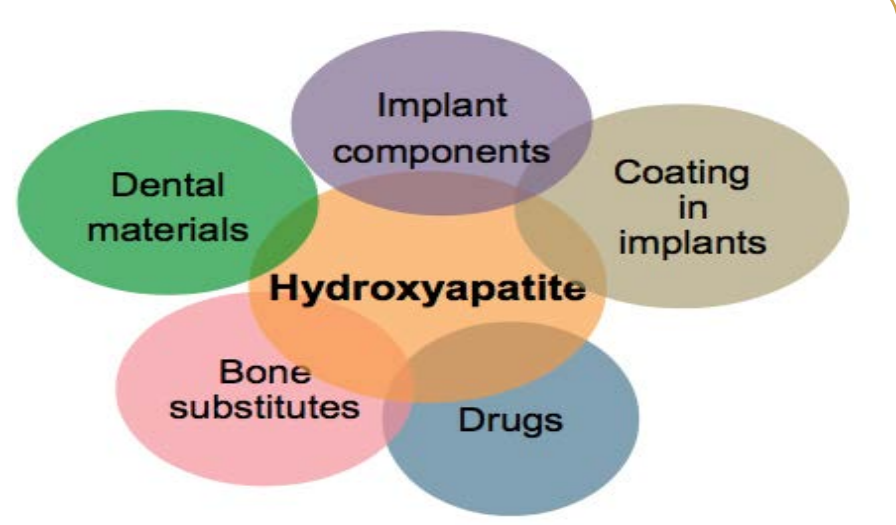

Figure 4 Applications of hydroxyapatite, there is also correlation between drugs and bone substitutes, components and implant coating.

toxic, so that degradation happens in conjunction with tissue formation and gradually be replaced by a new inter-positioned bone matrix in the region closest to the previous [22].

Mechanical properties: Ideally, the material should maintain the morphology, which is deployed, being sufficiently resistant to allow surgical handling during implantation and adapted to the recipient bed, and that bone remodeling is gradual [23].

Architecture: Currently, there are several conformity presentations structures such as paste, gel, powder, membrane, disc, block, granule, microsphere, among others - to meet the clinical needs of the professional. These materials have improved chemical composition and physical characteristics of the surface to favor regeneration [23] (Figures 2 and 3).

\section{Nanobiomaterials}

Nanotechnology terminology was first used by Nrio Taniguchi, in a scientific publication. The development of nanostructured materials or biomimetic changes has been important issue in fundamental and technological research, as the infinite possibilities of new associations or composites and improvements in various properties.

The bone is naturally and nanostructured materials with nanometer structure, ie size of less than $100 \mathrm{~nm}$, has been gaining attention in the bioengineering.

One of the nanostructuring of advantages is able to mimic the properties of the treated site, through changes in their mechanical, electrical line, optical, magnetic and citocompatíveis, in order to stimulate and/or act as needed to promote cell adhesion process and angiogenesis [23].

The biomimetic materials, when used in bone lesions must provide a framework that enables the adhesion, migration and proliferation of osteogenic lineage cells allowing deposition of osteoid matrix. Thus, the osteogenic potential is unlike proportional its physical and chemical characteristics, such as roughness, topography, crystallinity, mechanical strength, 
surface energy and create enough spaces for angiogenesis $[24,25]$.

The increased surface area of contact (collagen, fibronectin, and vitronectin amine) providing greater cell activity through integrin and celullar membrane receptors $[26,27]$.

\section{Bioapatita and hydroxyapatite}

In the human body the major components of bone is mineralized tissue, dentin and enamel which are composed of calcium phosphate mineral in a phase $(45-70 \%$ weight), water $(10 \%$ by weight) collagen (20-45 wt\%) and a small proportion of noncollagenous proteins representing the phase organic [28].

The bone mineral consists mainly of hydroxyapatite formulation $\left(\mathrm{Ca}_{10}\left(\mathrm{PO}_{4}\right) 6(\mathrm{OH})_{2}\right)$ associated with groups of smaller elements and trace elements, which play a vital role in bone metabolism and chemical reactions. The composition of bone apatite may vary due to having various crystallographic sites where the atomic exchanges can occur in many different elements and ionic charges which may be replaced [29].

The intended use of biomaterials used for bone replacement is guided by the ability of these materials to stimulate biochemical and cellular systems, so that mimic the biological material for replacement of apatite mineral loss previous [29]. The apatite name comes from the Greek "apatites" which means "misleading", where this definition is associated with lack of stoichiometry of the mineral, for a material with stoichiometric deficient and similarity of their crystalline structure hinder their identification [30]. The apatite and its deverivados, have been widely investigated. The first tile was used as a bone substitute the plaster in 1894, the first and bone defect repair with calcium phosphate was conducted in 1920 by Albee [30].

The behavior of bioapatitas should be attributed to its characteristics such as very small crystals, with consequently high solubility, low crystallinity, and low crystalline disorder stoichiometry [31]. The network structure of apatite and its crystallographic regions to make substitutions likely to enabling with different doping ions and substitutions of chemical elements in its composition. These substitutions affect their crystallinity (lattice parameters and crystal size) and its chemical-physical characteristics (solubility) [32]

The biological apatites differ in composition from pure $\mathrm{HA}$ at stoichiometry, morphology and crystals, have 1.63 to enamel, dentin and 1.61 to 1.71 for the bone, different from the stoichiometric $\mathrm{HA}\left(\mathrm{Ca}_{10}\left(\mathrm{PO}_{4}\right) 6(\mathrm{OH})_{2}\right.$ having their compliance ratio $\mathrm{Ca} / \mathrm{P}$ of 1.67 as well as in its constitution, which shows $39.9 \%$ of its weight of calcium, phosphate and $18.5 \% 3.38 \%$ of hydroxyl $[33,34]$ (Figure 4).

The solubility is influenced by the morphology of the material, crystal size and crystallinity of the apatite, thereby being the determining factor in its in vivo behavior will influence on their dissolution [35]. Indeed, hydroxyapatite can accommodate nearly half of the elements of the periodic table in compliance due to its high flexibility of its structure. Specifically, substitutions occur in the cationic sites occupied by $\mathrm{Ca}^{2+}$, and bivalent (e.g.,
$\mathrm{Sr}^{2+}, \mathrm{Ba}^{2+}, \mathrm{Mg}^{2+}$, etc.) as well as monovalent (e.g., $\mathrm{Na}^{+}, \mathrm{K}^{+}$, etc.) [36] (Table 1).

The alloplastic materials must interact with molecules of the organism, being biodegradable, bioactive, biocompatible, noncarcinogenic and non-toxic. The physical characteristics of calcium phosphate biomaterials are correlated with the shape and surface area can be fabricated into microspheres, powder, plates, membranes, screens, sponges and hydrogels. With respect to porosity, may be macro, dense or microporous, and its crystallinity can be crystalline or amorphous [37]. For the laboratory synthesis of HA are used, different techniques, such as precipitation, hydrolysis, hydrothermal synthesis or extracted from natural resources (fish bone, marine shells, eggshells and bovine bone).

Briefly, methods in solid starting material containing calcium and phosphate are mixed and calcined at high temperatures

Table 1: Chemical composition and lattice parameters of the mineral component of bone, enamel and dentine compared to stoichiometric HA [31,34].

\begin{tabular}{|c|c|c|c|c|}
\hline Element & Bone & Esmalt & Dentin & $\begin{array}{c}\text { HA } \\
\text { Stoichiometrics }\end{array}$ \\
\hline Calcio (Ca) & $34.80-36.6$ & $\begin{array}{c}36.50-37.60 \\
w t \%\end{array}$ & $40.30 w t \%$ & $39.60 \mathrm{wt} \%$ \\
\hline Fosforo (P) & $\begin{array}{c}15.20-17.10 \\
w t \%\end{array}$ & $\begin{array}{c}17.70-18.30 \\
w t \%\end{array}$ & 18.60 wt $\%$ & $18.50 \mathrm{wt} \%$ \\
\hline Sodio (Na) & $\begin{array}{c}0.90-1.00 \\
\text { wt } \%\end{array}$ & $\begin{array}{c}0.50-0.70 \\
\text { wt\% }\end{array}$ & $0.10 w t \%$ & -- \\
\hline Potassio (K) & $\begin{array}{c}0.03-0.07 \\
w t \%\end{array}$ & $\begin{array}{c}0.05-0.08 \\
w t \%\end{array}$ & 0.07 wt\% & -- \\
\hline $\begin{array}{l}\text { Magnesio } \\
\text { (Mg) }\end{array}$ & $\begin{array}{c}0.60-0.72 \\
w t \%\end{array}$ & $\begin{array}{c}0.20-0.44 \\
w t \%\end{array}$ & 1.10 wt\% & -- \\
\hline Estroncio (Sr) & $0-0.05 w t \%$ & $0.03 w t \%$ & 0.04 wt $\%$ & -- \\
\hline Zinco (Zn) & $\begin{array}{c}\text { 0-39.00 } \\
\text { ppm }\end{array}$ & 263 ppm & 173 ppm & -- \\
\hline Ferro (Fe) & -- & 118 ppm & 93 ppm & -- \\
\hline Prata (Ag) & -- & $0.60 \mathrm{ppm}$ & $2 \mathrm{ppm}$ & -- \\
\hline $\begin{array}{l}\text { Manganes } \\
\text { (Mn) }\end{array}$ & $0-0.17 \mathrm{ppm}$ & $0.60 \mathrm{ppm}$ & $2 \mathrm{ppm}$ & -- \\
\hline Bario (Ba) & -- & 125 ppm & 129 ppm & -- \\
\hline Aluminio (Al) & -- & 86 ppm & 69 ppm & -- \\
\hline Cobalto (Co) & $\begin{array}{c}0.0 .025 \\
\text { ppm }\end{array}$ & 0.10 ppm & $1 \mathrm{ppm}$ & -- \\
\hline Ouro (Au) & -- & 0.10 ppm & 0.07 ppm & -- \\
\hline $\begin{array}{l}\text { Antimonio } \\
\text { (Sb) }\end{array}$ & -- & $1 \mathrm{ppm}$ & 0.70 ppm & -- \\
\hline Chloro (Cl) & $\begin{array}{c}0.10-0.13 \\
w t \%\end{array}$ & $\begin{array}{c}0.30-0.40 \\
w t \%\end{array}$ & $0.27 w t \%$ & -- \\
\hline Fluor (F) & $\begin{array}{c}0.03-0.10 \\
w t \%\end{array}$ & 0.01 wt\% & 0.07 wt\% & -- \\
\hline Silica (Si) & $0-500$ ppm & -- & -- & -- \\
\hline Cromo (Cr) & $0-0.33$ ppm & $1 \mathrm{ppm}$ & $2 \mathrm{ppm}$ & -- \\
\hline Bromo (Br) & -- & 34 ppm & 114 ppm & -- \\
\hline \multicolumn{5}{|c|}{ Estruturas Parametricas } \\
\hline$\alpha$-axis & $9.410 / 9.49$ & 9.441 & 9.421 & $9.430 / 9.432 / 9.422$ \\
\hline C-axis & $6.890 / 6.880$ & $6.882 / 6.880$ & 6.887 & $6.891 / 6.881 / 6.880$ \\
\hline
\end{tabular}


(approximately $1000^{\circ} \mathrm{C}$ ) for specified time, are milled and mechanical energy is used to promote structural reactions. The dry methods do not require use of a solvent and chemical methods are simple methods of production of $\mathrm{HA}$, using various phosphor precursors and calcium [38]. In the sol-gel process, a colloidal suspension of solid particles is transformed into 3D network solid phase, where the precursors are also mixed, after aging, ice cream, dried and calcined to remove residual organic [39].

The wet synthesis is based on the reaction solution being held at various temperatures using different solvents and applying different chemicals, different cycles and different additives apparatus for controlling the precipitation. This method is considered the one that promotes closer hydroxyapatite with human bone. The emulsion allows the size and morphology of control and inhibits the formation of agglomerates, using materials of different kinds (e.g., oil in water) [40].

The combustion process produces a high purity product using a single step, requiring therefore a power supply to complete the reaction combustion [40]. In the hydrolysis, the HA is obtained by processing various calcium phosphates, especially in a water solution [41]. The hydrothermal is described as a chemical precipitation occurred at high temperatures, modifiers organic being used [42]. The sonochemical methods provide for the formation of uniform particles in the presence of ultrasonic radiation sonographic [43]. In pyrolysis particles formed in a gas phase reactant, generated by physical evaporation and spray sonic an ultrasonic generator [44].

In the above methods, it is possible to combine two or more methods to obtain HA with better properties, structural characteristics, and hydrothermal chemical mechanical combinations, hot water treatment, hydrolysis, hydrothermalmicroemulsion [45] (Figure 5). The properties obtained depend on the synthesis method, i.e., the ratio of $\mathrm{Ca} / \mathrm{P}$, temperature,

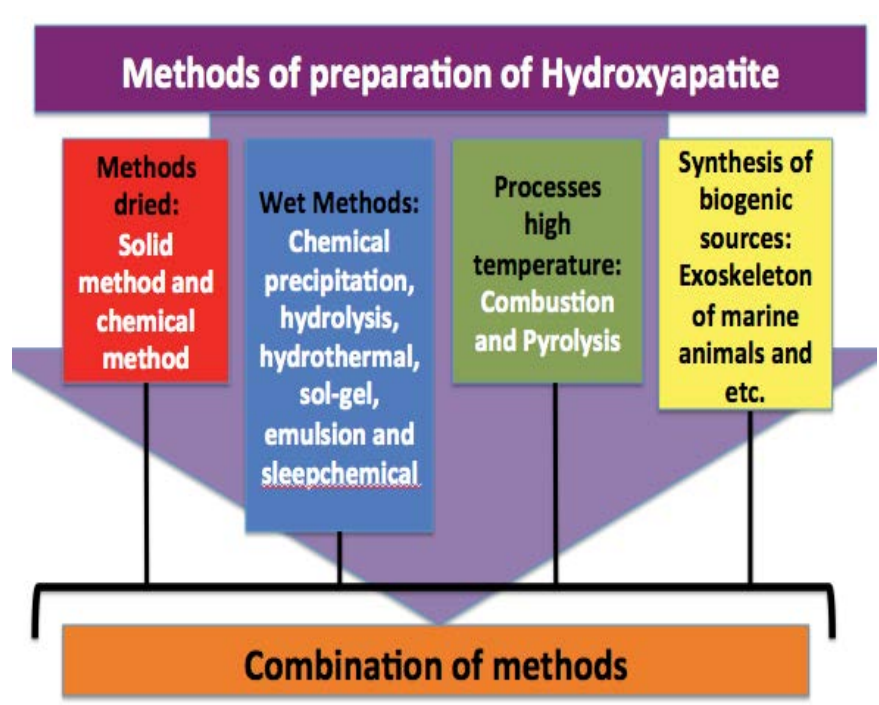

Figure 5

Organization Chart adapted for various methods of synthesis hydroxyapatite [46].
$\mathrm{pH}$, and the gelling time. Apart from its biocompatibility of these materials should provide cell viability, proliferation, providing adequate space for growth.

Biogenic sources can be organized into four groups.

- The first makes use of the eggshell reagents and exoskeleton of marine organisms;

- Second, from bovine cortical bone;

- Third, from biomolecules derived naturally and,

- Fourth, it uses the application of microwave radiation to activate the reaction [46].

The particle size also influences the porosity and surface area, where smaller particles or equal to $50 \mu \mathrm{m}$ ease of incorporation and have better adhesion bone cells [47]. The temperature is another important factor, being $25^{\circ}$ to $37^{\circ}$ is the optimum temperature required to obtain the closest hydroxyapatite synthesis process of the human bone and wet method is the method that produces HA closest to the bone tissue. Too high temperatures will not provide low stoichiometry [48].

Currently, 3D printing techniques attract great interest as a promising tool in the production of bone substitutes tailored to dental and medical application. It may soon be possible to restore large mineral loss exactly. The HA is an easy to prepare materials and has a low production cost, however, there is still a lot of efforts to be made to adapt biochemical structures, mechanical and biological and greater power of regeneration.

With scientific advances, we conjecture about materials development possibilities with the lowest operating cost, as the bone substitutes sold in the Brazilian market or imported burden treatment. These perspectives drive new research that, besides contributing to scientific advancement in this area of knowledge, enable reconstructive treatments can reach the most needy layers, thus benefiting a larger number of people than in developing countries such as Brazil, are large population.

\section{Substitute with metal bone}

Among the raw materials for obtaining or association with biomaterials, metals have highlighted due to high resistance to fatigue and the great mechanical performance. The most common applications are: Screws, fracture plates, wires, dental implants, prosthetic joints, as well as bone substitutes [49].

The great versatility of metals for use with biological materials, it should also, the possibility of surface abrasion, polishing and ease of sterilization without changing its structural compliance. For use safely in human body, these metals must provide some minimum requirements as to biocompatibility not produce inflammatory reactions, allergies or toxic, chemically stable [50]. In entando, biological apatites are different stoichiometric HA in various ways, including lack of stoichiometry, the small dimensions of the crystals, as well as low crystallinity and solubility [34].

From a chemical point of view, considering the properties of ions, anions and cations, which are used in some research, the replacement of an ionic or cationic grouping of a bone 
substitute may alter the biological, mechanical properties, surface charge, where these substitutions modify network crystallinity substantially influencing the solubility under physiological conditions, thus performing biological changes after implantation. The ease of the atomic doping of HA mainly with metals opened numerous opportunities for combinations [50]. Ions are as defined electrified atoms that have gained or lost electrons to the medium, when the number of protons is higher than the number of electrons, is called the cation, which is generally formed of alkali metals (family IA) and alkaline earth metals (family IIA) table periodic [51]. Cations which have +1 charge are called monopositivos those having +2 charge are called dipositivos and so sucessitivamente, e.g., $\mathrm{Mg}^{+2}, \mathrm{Ca}^{+2}$ and $\mathrm{Zn}^{+2}$ [52].

Anions possess a negative charge, for receiving one or more electrons resulting in a greater number of electrons with respect to protons, may also be monovalent (-1), divalent (-2) on, e.g., $\mathrm{Cl}^{-}$ $1, \mathrm{Br}^{-1}, \mathrm{~F}^{-1}$ [52]. The biological apatites have structural limitations, unlike the synthetic apatites where substitutions are possible such as $\mathrm{F}^{-}, \mathrm{Cl}^{-}, \mathrm{Na}^{+}, \mathrm{K}^{+}, \mathrm{Fe}^{2+}, \mathrm{Zn}^{2+}, \mathrm{Sr}^{2+}, \mathrm{Mg}^{2+}$, citrate and carbon. There limitations to quantiadade incorporation of ions, entretando are able to incorporate almost half of the periodic elements in its structure atomic [53] (Figure 6). The pure synthetic HA is not ideal for use as a bone substitute because of its brittleness, lack of strength and high degree of crystallinity, which results in reducing the degradability when it is implanted at a site. To have superior properties is indicated doped with one or more metals to improve their mechanical strength and forming bone [54].

Magnesium: Magnesium ( $\mathrm{Mg}$ ) is an element belonging to the alkaline earth family; it is found solid under ambient conditions. It is the eighth most abundant element in the earth ions crostra and their important roles in many activities and coenzymes ATP reactions and part of the human bone structure (2 wt\%) [55].

Its deficiency affects the skeletal metabolic stages, causing the demise of bone growth, decreased osteblástica and osteoclast activity, hence the weakness bone. Studies have shown that magnesium deficiency is directly correlated with osteoporosis negatively influencing all metabolic stages, with a result in the inhibition of bone growth, and osteoclast activity and frailty osteblastic bone [55]. The progressive reduction of the concentration of $\mathrm{Mg}^{2+}$ at the beginning of remodeling during the process of bone calcification is a clear sign of their participation in bone remodeling process [56].

Zinc: Zinc $(Z n)$ is found at room temperature in the solid state. It acts on the metabolism of proteins and nucleic acids, and stimulates several enzymes, supports the immune system, preservation of membrane structure and function, hormonal and antibacterial activity and wound healing.

Zn can be found in all biological tissues; however, the bone is their main site and its deficiency is associated with decreased density bone [57].

Some studies have demonstrated the great potential antibacterial $\mathrm{Zn}$, inhibiting bacterial and fungal growth, including $E$. coli, S.

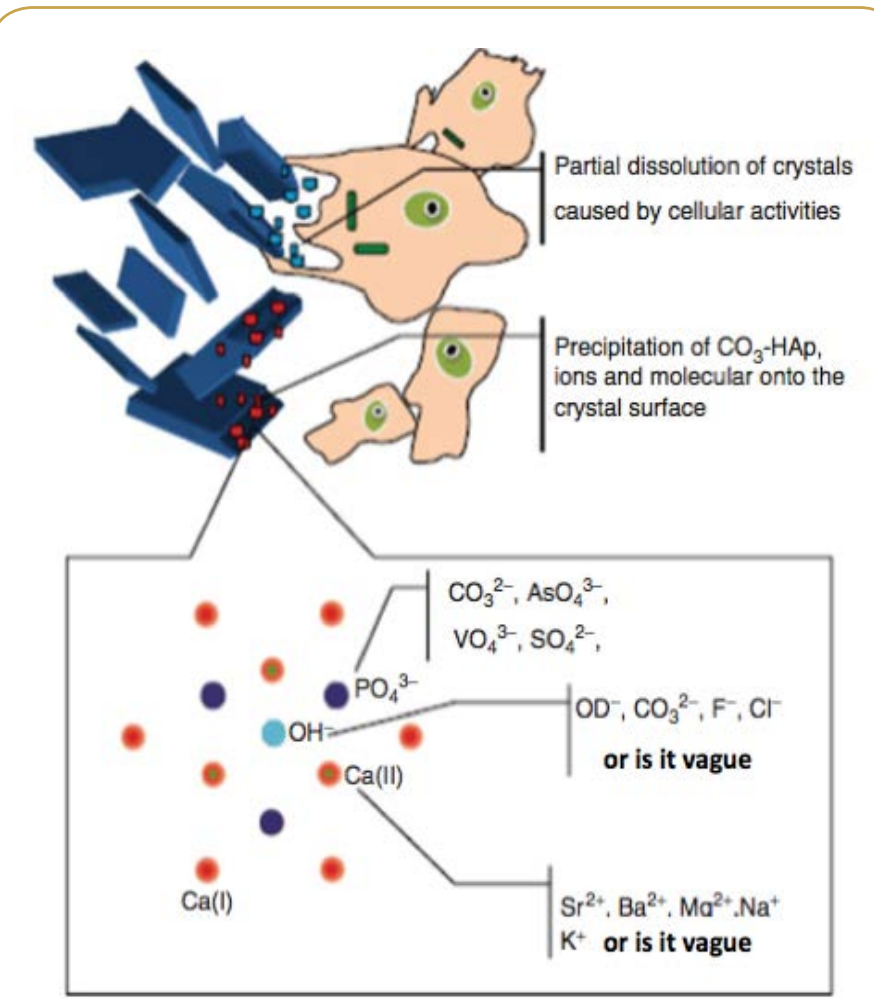

Figure 6 Schematic drawing of partial dissolution/precipitation in vivo biological apatites and ionic substitutions in HA where crystal is shown that cationic substitutions occur in the group of $\mathrm{Ca}$ (II) and the ionic substitutions to the hydroxyl group [54].

aureus, Candida albicans and S. mutans, however, requiring a content of more than 1000ppm to display an adequate antimicrobial effect. Consequently, the material having higher antibacterial property will miminizar the risk of infection and resorption in remodeling process [58-60].

Strontium: Strontium ( $\mathrm{Sr}$ ) is found at room temperature in the solid state. This element is present in the mineral phase of bone and participates in great works metabolic [61].

The literature has many studies using Sr osteoprose treatment, bone pain and treatment of bone cancer, may exert dual effects of stimulation of osteoblast differentiation and inhibiting the osteoclast resorption and bone [62-64].

Manganese: In the human body $\mathrm{Mn}$ affects bone remodeling, and its deficit causes a reduction in the synthesis of the organic matrix and delay endochondral osteogenesis [65]. The $\mathrm{Mn}^{2+}$ doped HA will strongly influence on the thermal stability of apatite besides will affect the bioactivity of material [66]. Of all the metals studied is the one with less usage in the literature.

Iron: Iron (Fe) is found in nature in solid state. It plays an important role in cellular metabolic process and is a key element for life in mammals. Its function is to transport oxygen in the blood, through the hemoglobin existing in red blood cells. It is present in liver, spleen, bone marrow, kidneys and intestine [67].

With their magnetic properties Fe allows their use in various 
biomedical applications, however, the synthesis of an excess of iron materials should be avoided because it affects the provision of atoms [68].

\section{Conclusion and Future Perspectives}

The search for an ideal biomaterial that mimics the lost mineral tissue continues motivating researchers' bioengineered area to discover materials that accelerate angiogenesis and provide a framework similar to human bone tissue. In clinical professional routine, the extra-oral autograft is already disuse, while on the intraoral graft gradually being replaced by composite biomaterials or graft (autograft associated with biomaterials), considering the reduced amount mineral extracted from the patient, with consequent lower morbidity. The condition of slow resorption and remodeling of the biomaterial is often a positive feature, since the remainder having a preserved; the biomaterial will help maintain the morphology, by having a slow corticalization.

\section{References}

1 Bukawa $H$ (2006) The engineering of craniofacial tissues in the laboratory: A review of schaffolds of biomaterials and implants coatings Dent. Clin N Am 50: 205-216.

2 Afonso AS (1998) interaction between biomaterials and bone tissue. 213f. Thesis (PhD) School of Dental Medicine, University of Porto, Porto, Portugal.

3 Nerem AT (2005) Bioengineered tissues: The science, the technology, and the industry. Orthod Craniofacial Res 8: 134-140.

4 Andia DC, Cerri PS, Spolidorio LC (2006) Bone tissue: Morphological and histophysiological aspects. J Dentistry 35: 191-198.

5 Rho JY, Kuhn-spearing L, Zioupos P (1998) Mechanical properties and the hierarchical structure of bone, medical engineering. Phys 20: 92-102.

6 Chiara (2012) Nanostructured biomaterials for tissue engineered bone tissue reconstruction. Int J Mol Sci 13: 737-757.

7 Simoes RD (1995) Aspects of bone metabolism osteoporosis. In: Endocrine Gynecology. (1st edn). São Paulo, Brazil.

8 Shekaran A, Garcia AJ (2011) Nanoscale engineering of extracellular matrix- mimetic bioadhesive surfaces and implants for tissue engineering. Biochimica et Biophysica Acta 1810: 350-360.

9 Atwood DA (1979) Bone Loss of alveolar ridge edentolous. J Periodont Special Tissue 1: 11-21.

10 Cardoso AL (2006) Histology and physiology of autogenous bone graft literature review. Innovations Implant J 1: 10-14.

11 Mota NL (2008) Embryology and histophysiology bone tissue: A review and leading histophysiological bases of metabolic bone diseases. Bulletin Reprod Biol Center 27: 27-32.

12 Zamprogno HCDDM (2004) Evaluation of bone grafting materials in cats: A Comparison of cancellous autograft, allograft cancellous and bioglass in the femoral defect model. Mississippi State University.

13 MISCH CE (2007) Contemporary implant dentistry. (3rd edn), St. Louis, Mosby, USA.

14 Souza MPG (2010) Diagnosis and treatment of osteoporosis. J Orthopedics 45: 220-229.
Biomaterials are increasingly in clinical practice of the professional, which helps the technical, scientific and industrial development. Science goes for a change at the molecular level of bone substitutes, by having biocompatibility and biodegradability, which are basic features, as well as for the search for a product that can provide the ideal morphology, bringing better quality of life to the needy.

It should be noted that, for the development of new implants, you must use reliable methodological processes and reliable to laboratory-controlled studies in pursuit of scientific support and subsequent dental-medical application, contributing to the health of the future. generations. The extra-oral autograft is in disuse for Dentistry and Medicine for very specific use. Hydroxyapatite is currently the material chosen as the basis for creating graft materials, although sheer is not ideal. The third and current generation of biomaterials is undergoing changes at the molecular level and may have an associated pharmacological function.

15 Dyce KM, Sack WO, Wensing CJG (2004) Anatomy veterinary treaty. (3rd edn), Rio de Janeiro: Guanabara Koogan, Brazil.

16 Croci AT (1997) Slow consolidation and nonunion. Acta Orthopedic Brazilian 5: 26-34.

17 Adams BR (2013) Osteoblast response to nanocrystalline calcium hydroxyapatite depends on carbonate content. J Biomed Mater Res 1: $2-4$.

18 Mazzoneto R, Netto HD, Birth FF (2012) Bone grafts in implant dentistry. (1st edn), Napoleon (Ed), England, UK.

19 Zhang L, Webster TJ (2009) Nanotechnology and nanomaterials: Promises for improved tissue regeneration. Nano Today 4: 66-80.

20 Conz MB (2005) Physicochemical characterization of six commercial hydroxyapatites for medical-dental applications the graft bone. J Appl Oral Sci 13: 136-140.

21 Holzapfel BM, Reichert JC, Schantz JT, Gbureck P (2013) How smart do biomaterials need to be? A translational science and clinical point of view. Adv Drug Deliv Rev 65: 581-603.

22 Kawachi EY (2000) Bioceramics: Trends and prospects of an interdisciplinary area. New Chem 23: 518-522.

23 Muncibì FPDC, Carulli MFC, Nistri G, Innocenti M (2011) Long term results of percutaneous fixation of proximal humerus fractures. Indian J Orthop 1: 2-4.

24 Boyce BF (1999) Recent advances in bone biology Provide insight into pathogenesis of bone diseases. Lab Invest 79: 83-94.

25 Burg KJL, Porter S, Kelam JF (2000) Biomaterial developments for bone tissue engineering. Biomaterials 21: 2347-2359.

26 Carano AD, Filvaroff EH (2003) Angiogenesis and bone repair. Drug Disc Today 8: 980-984.

27 Pasteris JD, Wopenka B, Valsami EJ (2008) Bone and tooth mineralization: Why apatite? Elements 4: 97-104.

28 Skinner HCW (2005) Biominerals. Mineral Mag 69: 621-641.

29 Mendes FAA (2006) Synthesis and characterization of hydroxyapatite composites from recycled raw material $181 \mathrm{f}$. Thesis: Doctorate in Materials Engineering, Federal -University of Ouro Preto School of Mines. Thematic Network in Materials Engineering, Ouro Preto. 
30 Elliott JC (1994) Structure and chemistry of the apatites and other calcium orthophosphates. Elsevier, Amsterdam, The Netherlands.

31 Salinas AJ, Vallet EPF (2013) A tissue engineering approach based on the use of bioceramics for bone repair. Biomater Sci 1: 40-51.

32 Inagaki M, Kameyama $T$ (2007) Phase transformation of the plasma-sprayed hydroxyapatite coating with preferred crystalline orientation. Biomaterials 28: 2923-2931.

33 Legeros RZ (1994) Biological and synthetic apatites. In: Hydroxyapatite and related materials, Boca Raton: CRC Press.

34 LeGeros RZ (2008) Calcium phosphate-based osteoinductive materials. Chem Rev 108: 4742-4753.

35 Wopenka B, Pasteris JD (2005) The mineralogical perspective on the apatite in bone. Mat Sci Eng C-Bio S 25: 131-143.

36 Hughes JM, Rakovan J (2002) The crystal structure of apatite, $\mathrm{Ca}_{5}\left(\mathrm{PO}_{4}\right)_{3}(\mathrm{~F}, \mathrm{OH}, \mathrm{Cl})$. In: Phosphates: geochemical and geobiological importance material. Mineralogy and Geochemistry reviews, Mineralogical Society of America, Washington, USA.

37 Miguel FB (2006) Morphological assessment of the behavior of three-dimensional matrices anionic collagen in bone regeneration in rats. J Biomed Mater Res B Appl Biomater 78: 334-339.

38 Miguel FB (2013) Regeneration of critical defects with bone matrix the anionic collagen scaffolds. J Mater Sci Mater Med 24: 2567-2575.

39 Porter AE, Patel N, Skepper JN, Best SM, Bonfield W (2003) Comparison of in vivo dissolution processes hydroxyapatite and silicon-Substituted hydroxyapatite bioceramics. Biomaterials 24: 4609-4620.

40 Patel N, Best SM, Bonfield W, Gibson IR, Damien P, et al. (2002) A comparative study on the in vivo behavior of hydroxyapatite and hydroxyapatite granules silicon Substituted. J Mater Sci Mater Med 13: 1199-1206.

41 Vallet-Region M, Arcos D (2005) Silicon Substituted hydroxyapatites. The calcium phosphate method to upgrade based implants. J Mater Chem 15: 1509-1516.

42 Pietak AM, Reid JW, Stott MJ, Sayer M (2007) Silicon substitution in the calcium phosphate bioceramics. Biomaterials 28: 4023-4032.

43 Tang XL, Xiao XF, Liu RF (2005) Structural characterization of siliconSubstituted hydroxyapatite synthesized by the hydrothermal method. Mater Let 59: 3841-3846.

44 Botelho CM, Brooks RA, Best MS, Lopes JD, Santos N, et al. (2006) Human osteoblast response to silicon-Substituted hydroxyapatite. J Biomed Mater Res 79A: 723-730.

45 Sadat-Shojai M, Khorasani MT, Khoshdargi D, Jamshidi A (2013) Synthesis methods for nanosized hydroxyapatite with diverse structures. Acta Biomater 9: 7591-7521.

46 Wang Z, Xu Z, Zhaoa W, Sahai N (2015) Potential mechanism for amino acid-controlled crystal growth of hydroxyapatite. J Mater Chem B 3: 9157-9167

47 Gregoire M, Orly I, Menanteau J (1990) The influence of calcium phosphate biomaterials on human bone cell activities. An in vitro approach. J Biomed Mat Res 24: 165-177.

48 Araujo TS, Santos-Filho JB (2008) pure hydroxyapatite doped with $\mathrm{Cr}^{3++}$ : production, properties and application in biosensors. (1st edn), Aracaju.
49 Sumita M, Hanawa T, Teoh SH (2004) Corrosion behavior of nitrogen stainless steel in Ringer's solution. Mat Sci Eng 24: 753.

50 Ratner BD, Hoffman AS, Schoen FJ, Lemons JE (2013) Ann Introduction to materials in medicine. IN: Biomaterials Science. History of Biomaterials, Eds Elsevier: Oxford, UK.

51 Hao Y, Yan H, Wang X (2012) Evaluation of osteoinduction and proliferation nano-Sr-PAH on: The novel orthopedic biomaterial for bone tissue regeneration. J Nanosci Naotechnol 12: 207-221.

52 Hughes JM, Rakovan J (2002) The crystal structure of apatite, $\mathrm{Ca}_{5}\left(\mathrm{PO}_{4}\right)_{3}(\mathrm{~F}, \mathrm{OH}, \mathrm{Cl})$. In: Phosphates: geochemical, and geobiological importance material in Mineralogy and Geochemistry reviews, Mineralogical Society of America, Washington, USA.

53 Liu Q, Huang S, JP Matinlinna, Chen Z, Pan H (2013) Insight into biological apatite: Physiochemical properties and preparation approaches. BioMed Res Int 2013: 1-13.

54 Bigi A, Boanini C, Capuccini M (2007) Strontium-substituted hydroxyapatite nanocrystals. Inorg Chim Acta 360: 1009-1116.

55 Percival M (1999) Bone health and osteoporosis. Rep Appl Nutr Sci 5: 1-5.

56 Bigi A, Foresti R, Gregoriani R (1992) The role of magnesium on the structure of biological apatites. Calcif Tissue Int 50: 439-444.

57 Barrea R, Perez CA, Ramos AY (2003) Distribution and incorporation of zinc in biological calcium phosphates. X-Ray Spectrum 32: 387-395.

58 Thian ES, Konishi T, Kawanobe Y, Lim PN, Choong C, et al. (2013) Zinc- Substituted hydroxyapatite: A biomaterial with enhanced, and bioactivity antibacterial properties. J Mater Sci Mater Med 24: 437-445.

59 Stanic V, Dimitrijevic S, Antic-Stankovic J, Mitric M, Jokic B, et al. (2010) Synthesis, characterization and antimicrobial activity of copper and zinc-doped hydroxyapatite nanopowders. Surf Sci Appl 256: 6083-6089.

60 Velard M, Maquin LD, Braux J, Guillaume C, Bouthors S, et al. (2010) The effect of zinc hydroxyapatite-mediated on activation of human polymorphonuclear neutrophils and implant-associated acute Hat inflammation. Biomaterials 31: 2001-2009.

61 Blake GM, Zivanovic MA, McEwan AJ, Ackery MD (1986) SR-89 therapy- strontium kinetics in disseminated carcinoma of the prostate. Eur J Nucl Med 12: 447-454.

62 Dahl SGP, Marie PJ, Mauras Y, Boivin G, Ammann P, et al. (2001) Incorporation and distribution of strontium in bone. Bone 28 : 446-453.

63 Robinson RG, Spicer JA, Preston DF, Wegst AV, Martin NL (1987) Treatment of metastatic bone pain with strontium-89. Int J Rad Appl Instrum 14: 219-222.

64 Bonnelye E, Chabadel A, Saltel F, Jurdic P (2008) Dual effect of strontium ranelate: Stimulation of osteoblast differentiation and inhibition of osteoclast formation and resorption in vitro. Bone 42 : 129-138.

65 Medvecky L, Štulajterova R, Parilak G, Trpčevska J, Durišin J, et al. (2006) Influence of manganese on stability and particle growth of hydroxyapatite in simulated body fluid. Colloids Surf A 281: 221-229.

66 Mayer I, Cuisinier FJG, Popov R, Schleich Y, Gdalya S, et al. (2006) Phase relations between $\beta$-tricalcium phosphate and hydroxyapatite 
with manganese (II): Structural and spectroscopic properties. Eur J Inorg Chem 7: 1460-1465.

67 Zuo KH, Zeng YP, Jiang D (2012) Synthesis and magnetic property of irons-doped hydroxyapatite. J Nanosci Nanotechnol 12: 7096-7100.
68 Pon-On Meejoo W, Tang SM (2007) Iron into Incorporation of nano hydroxyapatite particles synthesized by the microwave process. Int J Nanosci 6: 9-16. 